\title{
Quantifying Iconicity's Contribution during Language Acquisition: Implications for Vocabulary Learning
}

\author{
Dominic W. Massaro ${ }^{1 *}$ and Marcus Perlman ${ }^{2}$ \\ 'Department of Psychology, University of California Santa Cruz, Santa Cruz, CA, USA, ${ }^{2}$ Language and Cognition \\ Department, Max Planck Institute for Psycholinguistics, Nijmegen, Netherlands
}

\section{OPEN ACCESS}

Edited by:

Morten H. Christiansen, Cornell University, USA

Reviewed by: Padraic Monaghan, Lancaster University, UK Jamie Reilly,

Temple University, USA

*Correspondence: Dominic W. Massaro massaro@ucsc.edu

Specialty section: This article was submitted to Language Sciences,

a section of the journal Frontiers in Communication

Received: 01 September 2016 Accepted: 13 February 2017 Published: 09 March 2017

Citation: Massaro DW and Perlman M (2017) Quantifying Iconicity's Contribution during Language Acquisition: Implications for Vocabulary Learning. Front. Commun. 2:4. doi: 10.3389/fcomm.2017.00004
Previous research found that iconicity - the motivated correspondence between word form and meaning - contributes to expressive vocabulary acquisition. We present two new experiments with two different databases and with novel analyses to give a detailed quantification of how iconicity contributes to vocabulary acquisition across development, including both receptive understanding and production. The results demonstrate that iconicity is more prevalent early in acquisition and diminishes with increasing age and with increasing vocabulary. In the first experiment, we found that the influence of iconicity on children's production vocabulary decreased gradually with increasing age. These effects were independent of the observed influence of concreteness, difficulty of articulation, and parental input frequency. Importantly, we substantiated the independence of iconicity, concreteness, and systematicity-a statistical regularity between sounds and meanings. In the second experiment, we found that the average iconicity of both a child's receptive vocabulary and expressive vocabulary diminished dramatically with increases in vocabulary size. These results indicate that iconic words tend to be learned early in the acquisition of both receptive vocabulary and expressive vocabulary. We recommend that iconicity be included as one of the many different influences on a child's early vocabulary acquisition.

\section{Keywords: vocabulary acquisition, speech difficulty, iconicity in speech, age of acquisition, parental input} frequency, child-directed speech

Facing the logically insurmountable challenge to link the form of a novel word (e.g., "gavagai") with its particular meaning (e.g., "rabbit"; Quine, 1960, 1990/1992), children manage to learn words with incredible ease. Interest in this process has permeated empirical and theoretical research in developmental psychology, psycholinguistics, and language studies more generally. Investigators have studied which words are learned and when they are learned (Fenson et al., 1994), biases in word learning (Markman, 1990, 1991); the perceptual, social, and linguistic properties of the words (Gentner, 1982; Waxman, 1999; Maguire et al., 2006; Vosoughi et al., 2010), the structure of the language being learned (Gentner and Boroditsky, 2001), and the influence of the child's milieu on word learning (Hart and Risley, 1995; Roy et al., 2015). A growing number of studies also show that the iconicity of words might be a significant factor in word learning (Imai and Kita, 2014; Perniss and Vigliocco, 2014; Perry et al., 2015).

Iconicity refers generally to a correspondence between the form of a signal (e.g., spoken word, sign, and written character) and its meaning. For example, the sign for tree is iconic in many signed languages: it resembles a branching tree waving above the ground in American Sign Language, 
outlines the shape of a tree in Danish Sign Language and forms a tree trunk in Chinese Sign Language. In contrast to signed languages, the words of spoken languages have traditionally been treated as arbitrary, with the assumption that the forms of most words bear no resemblance to their meaning (e.g., Hockett, 1960; Pinker and Bloom, 1990). However, there is now a large body of research showing that iconicity is prevalent in the lexicons of many spoken languages (Nuckolls, 1999; Dingemanse et al., 2015).

Most languages have an inventory of iconic words for soundsonomatopoeic words such as splash, slurp, and moo, which sound somewhat like the sound of the real-world event to which they refer. Rhodes (1994), for example, counts more than 100 of these words in English. Many languages also contain large inventories of ideophones - a distinctively iconic class of words that is used to express a variety of sensorimotor-rich meanings (Nuckolls, 1999; Voeltz and Kilian-Hatz, 2001; Dingemanse, 2012). For example, in Japanese, the word "koron"-with a voiceless [k] refers to a light object rolling once, the reduplicated "korokoro" to a light object rolling repeatedly, and "gorogoro" - with a voiced [g] - to a heavy object rolling repeatedly (Imai and Kita, 2014). And in Siwu, spoken in Ghana, ideophones include words like fwefwe "springy, elastic" and saaa "cool sensation" (Dingemanse et al., 2015). Outside of onomatopoeia and ideophones, there is also evidence that adjectives and verbs-which also tend to convey sensorimotor imagery-are also relatively iconic (Nygaard et al., 2009; Perry et al., 2015).

Another domain of iconic words involves some correspondence between the point of articulation of a word and its meaning. For example, there appears to be some prevalence across languages of nasal consonants in words for nose and bilabial consonants in words for lip (Urban, 2011). Spoken words can also have a correspondence between a word's meaning and other aspects of its pronunciation. The word teeny, meaning small, is pronounced with a relatively small vocal tract, with high front vowels characterized by retracted lips and a high-frequency second formant (Ohala, 1994). Thus, teeny can be recognized as iconic of "small" (compared to the larger vocal tract configuration of the back, rounded vowel in huge), a pattern that is documented in the lexicons of a diversity of languages (Ultan, 1978; Blasi et al., 2016).

Lewis and Frank (2016) have studied a more abstract form of iconicity that more meaningfully complex words tend to be longer. An evaluation of many diverse languages revealed that conceptually more complex meanings tend to have longer spoken forms. In their study, participants tended to assign a relatively long novel word to a conceptually more complex referent. Understanding that more complex meaning is usually represented by a longer word could aid a child's parsing of a stream of spoken language and thus facilitate word learning.

Some developmental psychologists have theorized that iconicity helps young children learn words by "bootstrapping" or "bridging" the association between a symbol and its referent (Imai and Kita, 2014; Perniss and Vigliocco, 2014). According to this idea, children begin to master word learning with the aid of iconic cues, which help to profile the connection between the form of a word and its meaning out in the world. The learning of verbs in particular may benefit from iconicity, as the referents of verbs are more abstract and challenging for young children to identify (Gentner, 1982; Snedeker and Gleitman, 2004). By helping children gain a firmer grasp of the concept of a symbol, iconicity might set the stage for the ensuing word-learning spurt of non-iconic words.

The hypothesis that iconicity plays a role in word learning is supported by experimental studies showing that young children are better at learning words-especially verbs-when they are iconic (Imai et al., 2008; Kantartzis et al., 2011; Yoshida, 2012). In one study, for example, 3-year-old Japanese children were taught a set of novel verbs for actions. Some of the words the children learned were iconic ("sound-symbolic"), created on the basis of iconic patterns found in Japanese mimetics (e.g., the novel word nosunosu for a slow manner of walking; Imai et al., 2008). The results showed that children were better able to generalize action words across agents when the verb was iconic of the action compared to when it was not. A subsequent study also using novel verbs based on Japanese mimetics replicated the finding with 3-year-old English-speaking children (Kantartzis et al., 2011). However, it remains to be determined whether children trained in an iconic condition can generalize their learning to a non-iconic condition that would not otherwise be learned.

Children as young as 14 months of age have been shown to benefit from iconicity in word learning (Imai et al., 2015). These children were better at learning novel words for spikey and rounded shapes when the words were iconic, corresponding to kiki and bouba sound symbolism (e.g., Köhler, 1947; Ramachandran and Hubbard, 2001).

If iconic words are indeed easier to learn, there should be a preponderance of iconic words early in the learning of natural languages. There is evidence that this is the case in signed languages, which are widely recognized to contain a prevalence of iconic signs [Klima and Bellugi, 1979; e.g., as evident in Signing Savvy (2016)]. Although the role of iconicity in sign acquisition has been disputed [e.g., Orlansky and Bonvillian, 1984; see Thompson (2011) for discussion], the most thorough study to date found that signs of British Sign Language (BSL) that were learned earlier by children tended to be more iconic (Thompson et al., 2012). Thompson et al.s measure of the age of acquisition of signs came from parental reports from a version of the MacArthurBates Communicative Development Inventory (MCDI; Fenson et al., 1994) adapted for BSL (Woolfe et al., 2010). The iconicity of signs was taken from norms based on BSL signers' judgments using a scale of 1 (not at all iconic) to 7 [highly iconic; see Vinson et al. (2008), for norming details and BSL videos].

Thompson et al. (2012) found a positive correlation between iconicity judgments and words understood and produced. This relationship held up even after controlling for the contribution of imageability and familiarity. Surprisingly, however, there was a significantly stronger correlation for older children (21- to 30-month olds) than for younger children (age 11- to 20-month olds). Thompson et al. suggested that the larger role for iconicity for the older children may result from their increasing cognitive abilities or their greater experience in understanding meaningful form-meaning mappings. However, this suggestion does not fit 
with the expectation that iconicity should play a larger role earlier in language use. Thus, although supporting a role for iconicity in word learning, the larger influence for older children is inconsistent with the bootstrapping hypothesis, in which iconicity should play a larger role earlier in vocabulary learning (Imai and Kita, 2014; Perniss and Vigliocco, 2014).

There is also evidence in spoken languages that earlier learned words tend to be more iconic. Perry et al. (2015) collected iconicity ratings on the roughly 600 English and Spanish words that are learned earliest by children, selected from their respective MCDIs. Native speakers on Amazon Mechanical Turk rated the iconicity of the words on a scale from -5 to 5 , where 5 indicated that a word was highly iconic, -5 that it sounded like the opposite of its meaning, and 0 that it was completely arbitrary. Their instructions to raters are given in the Appendix because the same instructions were used for acquiring our iconicity ratings.

The Perry et al. (2015) results showed that the likelihood of a word in children's production vocabulary in both English and Spanish at 30 months was positively correlated with the iconicity ratings, even when several other possible contributing factors were partialed out, including log word frequency, concreteness, and word length. The pattern in Spanish held for two collections of iconicity ratings, one with the verbs of the 600 -word set presented in infinitive form, and one with the verbs conjugated in the third person singular form. In English, the correlation between age of acquisition and iconicity held when the ratings were collected for words presented in written form only and in written form plus a spoken recording. It also held for ratings based on a more implicit measure of iconicity in which participants rated how accurately a space alien could guess the meaning of the word based on its sound alone.

The pattern in English also held when Perry et al. (2015) factored out the systematicity of words [taken from Monaghan et al. (2014)]. Systematicity is measured as a correlation between form similarity and meaning similarity - that is, the degree to which words with similar meanings have similar forms. Monaghan et al. computed systematicity for a large number of English words and found a negative correlation with the age of acquisition of the word from 2 to $13+$ years of age-more systematic words are learned earlier. Monaghan et al. (2014) and Christiansen and Chater (2016) observe that consistent sound-meaning patterns may facilitate early vocabulary acquisition, but the child would soon have to master arbitrary relationships necessitated by increases in vocabulary size.

In theory, systematicity, sometimes called "relative iconicity," is independent of iconicity. For example, the English cluster gl- occurs systematically in several words related to "vision" and "light," such as glitter, glimmer, and glisten (Bergen, 2004), but the segments bear no obvious resemblance to this meaning. Monaghan et al. (2014) question whether spoken languages afford sufficient degrees of articulatory freedom for words to be iconic but not systematic. As evidence, they give the example of onomatopoeic words for the calls of small animals (e.g., peep and cheep) versus calls of big animals (roar and grrr), which would systematically reflect the size of the animal.

Although Perry et al. (2015) found a positive effect of iconicity at 30 months, they did not evaluate its influence across the first years of a child's life. To address this question, we conduct a more detailed examination of the time course of iconicity in word learning across the first 4 years of expressive vocabulary acquisition. In addition, we examine the role of iconicity in the acquisition of receptive vocabulary as well as productive vocabulary. There is some evidence that although receptive vocabulary and productive vocabulary are correlated with one another, a variable might not have equivalent influences on these two expressions of vocabulary. Massaro and Rowe (2015), for example, showed that difficulty of articulation had a strong effect on word production but not word comprehension. Thus, it is possible that the influence of iconicity on vocabulary development differs between production and comprehension. In particular, a larger influence on comprehension might follow from the emphasis of the bootstrapping hypothesis on iconicity serving to perceptually cue children to the connection between the sound of a word and its meaning.

\section{EXPERIMENT 1: CHILDREN'S EXPRESSIVE VOCABULARY ACROSS ACQUISITION}

\section{Method}

The Office of Research Compliance Administration of the University of California Santa Cruz reviewed the proposed use of human subjects and determined that the project (UCSC IRB Protocol \# 2719) is exempt from IRB review. The UCSC IRB operates under a Federalwide Assurance approved by the DHHS Office for Human Research Protections, FWA00002797. The DHHS IRB Registration Number is IRB00000266.

The goal of the first experiment was to assess the influence of iconicity in children's productive vocabulary across the first 4 years of life. To determine the unique contribution of iconicity at successive stages of acquisition, we also examined several other variables known to influence word learning, including parental input word frequency (Goodman et al., 2008; Massaro, 2016), difficulty of articulation (Massaro and Rowe, 2015), imageability, concreteness, and systematicity (Monaghan et al., 2014). The following gives a description of these independent variables and the dependent variable for productive vocabulary used in the analyses.

\section{Iconicity Ratings}

We collected iconicity ratings for the 644 words from the MCDI, a normed list given to parents to measure the early productive vocabulary of 16- to 30-month-old toddlers learning American English (MCDI Words and Sentences; Fenson et al., 1993, 1994; Bates and Goodman, 1999; WordBank, 2016). The list includes nouns, verbs, adjectives, function or closed class words, and sound effects. The MCDI uses a checklist to ask parents to report their child's word production. A produced word requires that the child's utterance could be understood out of context by at least a parent or caregiver. The child is not given credit for produced words that are simply imitated, as in the case when the parent simply asks the child, "Can you say 'banana'?" We asked 15 students in the Santa Cruz community to rate the iconicity of all 
644 words, presented in written form in a different random order for each student.

The instructions were identical to those used by Perry et al. (2015) and are given in the Appendix. These instructions clarify how iconicity is being operationalized. As stated in the instructions, the onomatopoeic word slurp might be rated high in iconicity because the spoken word sounds like the audible event to which it refers. A relatively high iconicity rating might also be given to the word teeny because it sounds small and refers to something small. In contrast, the word microorganism implies something small but sounds big and therefore might receive a negative iconicity rating (Hockett, 1960). Words with no obvious relationship between the sound of the word and its meaning would be rated neutral. The independent variable for iconicity used in our analyses is the average iconicity rating across the 15 students. Table 1 gives four subsets of words that were rated as high, some, low, and opposite iconicity, respectively.

\section{Articulation Difficulty}

A child's ability to produce words, and more generally to learn those words, might relate to how difficult they are to articulate. Those words easier to articulate may tend to be acquired more easily than those that are more difficult. Massaro and Rowe (2015) showed evidence for this hypothesis by creating a metric of articulation difficulty of words based on their consonant phonemes. Articulation difficulty of the consonant segments was defined as a 1-7 value on a scale of easy to difficult based on several relevant studies (Smit et al., 1990; Smit, 1993; Stoel-Gammon and Buder, 1999; Kirk and Demuth, 2005; Rvachew et al., 2007; Kirk, 2008; McAllister Byun, 2012). Following Massaro and Rowe (2015),

TABLE 1 | Four groups of $\mathbf{2 6}$ words each differing in iconicity (the degree to which the sound of a word represents its meaning) as rated by 15 participants on a scale from -5 to +5 .

\begin{tabular}{llll}
\hline High & Some & Neutral & Opposite \\
\hline cockadoodledoo & pretzel & about & big \\
shh & push & bed & sandwich \\
baa & swim & behind & diaper \\
grr & too & camera & long \\
moo & above & church & much \\
choo-choo & cracker & closet & butterfly \\
meow & dirty & cloud & present \\
uh oh & don't & crib & tiger \\
clap & home & deer & bus \\
woof & kiss & does & kleenex \\
quack & melon & eat & pajamas \\
vroom & on & farm & park \\
yucky & peas & grapes & raisin \\
ouch & pool & if & comb \\
owie & pull & like & hamburger \\
pop & stay & of & penny \\
splash & stone & owl & sun \\
knock & fall & pretend & vanilla \\
peekaboo & hate & read & which \\
zipper & shovel & shirt & yard \\
bee & smile & the & breakfast \\
bubbles & stuck & tights & mouse \\
bump & tired & walk & napkin \\
hurry & turn & water & babysitter \\
stop & woods & when & porch \\
& & &
\end{tabular}

we assume that the difficulty of articulation of a word is simply the sum of the articulation difficulty of each of its consonants. These difficulty values correlate very highly with those derived by Shriberg (1993) who categorized 24 speech segments into early, middle, and late acquisition classes with 8 segments per class. Other possible influences, such as vowel identity, coarticulation, and the order of segments, were not included in the measure. However, despite these limitations, our measure of articulation difficulty has accounted for significant variability in vocabulary acquisition (Massaro and Rowe, 2015; Massaro, 2016). The assignment of articulation difficulty of English consonants is given in Table 2.

\section{Parental Input Word Frequency}

It is well established that the words children know are highly correlated with those that they have heard produced by their parents. Our measure of parental input word frequency was derived from the parental vocabulary corpus, a subset of the Child Language Data Exchange System corpora (CHILDES; MacWhinney, 2000; CHILDES, 2015). This database consists of the contributions of 27 individual corpora provided by 27 different investigators (ParentFreq, 2015). It contains a total of 2,579,966 word tokens, with 24,156 word types (counting all inflected forms of a word as separate types), consisting of spoken utterances from parents, caregivers, and experimenters produced in the presence of children spanning a range of ages (age: $0 ; 7-7 ; 5$; mean age: 3 years; ParentFreq, 2015). Thus, the corpus provides a huge sample of the speech to which children are exposed (e.g., dinner table talk, talk during free play, and storytelling), even though not all of the utterances are strictly child directed. We used log 10 parental
TABLE 2 | Difficulty of articulation measures for each consonant used in computing the difficulty of articulation of each word (given by the sum of the difficulty measures of all of the consonants in the word).

\begin{tabular}{llc}
\hline Phonemes & Example word & Articulation difficulty \\
\hline b & bin & 1 \\
d & date & 1 \\
h & help & 1 \\
m & mail & 1 \\
p & pin & 1 \\
f & fax & 2 \\
g & gap & 2 \\
j & yacht & 2 \\
k & king & 2 \\
n & nose & 2 \\
t & tip & 2 \\
D & this & 3 \\
T & thing & 3 \\
W & will & 3 \\
I & leg & 4 \\
v & very & 5 \\
dZ & gin & 6 \\
S & shop & 6 \\
tS & chin & 7 \\
N & long & 7 \\
r & ring & 7 \\
S & sing & 7 \\
Z & zip & 7 \\
Z & vision & 7
\end{tabular}


input frequency as the measured influence of parental input on a child's vocabulary.

\section{Concreteness and Imageability}

Concreteness refers to the extent to which a word can be experienced by the senses. Imageability, on the other hand, refers to the extent to which a word evokes a mental image. These two descriptions are very similar, and, therefore, it is not surprising that the obtained measures are highly correlated with one another. Several studies have shown that words that are higher in imageability and concreteness tend to be learned earlier in acquisition (Gillette et al., 1999). McDonough et al. (2011) found that imageability accounted for about $10 \%$ of the variance, after syntactic category (noun or verb) and frequency were partialed out. Their sample was limited to just 120 words that had imageability ratings, however. Early measures came from adults who have been asked to rate imageability and concreteness on a 7-point scale (Paivio et al., 1968; MRCDatabase, 2015). We found 437 words in this database that had both imageability and concreteness ratings. The correlation between imageability and concreteness was $r=0.94$. Given this high correlation, we used concreteness ratings from Brysbaert et al. (2014), which included ratings for 610 of our 644 test words.

It should also be noted that we expected our measure of iconicity to be fairly independent of concreteness, which is usually taken to define how easy it is to imagine a word given the word's meaning. Iconicity, on the other hand, refers to how easy it is to imagine a word given the word's sound. Other recent results support the distinction of iconicity from visual salience and concreteness (Winter et al., in press).

\section{Systematicity}

Monaghan et al. (2014) measured the systematicity for a set of 2,910 monosyllabic English words by assessing the contribution of each word to an overall form-meaning correlation across the full set of words. Although their systematicity measures overlapped with only 305 of our 644 words, we tested how well it predicts the time course of vocabulary acquisition for this subset of words.

\section{Children's Word Frequency}

As a measure of age of acquisition, Perry et al. (2015) used the percentage of children who produce that word at a given age from the MCDI database. There are several limitations to this variable as a measure of vocabulary acquisition. For one, it does not reflect how well a child knows a word or how frequently a child says a word. It also depends on parental reports, which might be somewhat fallible and biased (Tomasello and Mervis, 1994). Most importantly, the total number of children in the database is only 1,461 across the 14 months between 16 and 30 months of age. Thus, there are only about 100 children at each month, a small number relative to other available databases.

To provide a larger, more comprehensive database, in the first experiment of this study, we used the child production data from part of the CHILDES (2015) database. This database consists of 5,000 transcriptions of children's speech with 3,500,000 word tokens and spans children from birth to 7 years of age (Baath, 2014; ChildFreq, 2015). Notably, we use word frequency in the
ChildFreq database as a measure of vocabulary acquisition. The more often a word occurs in an age range, it is reasoned that the more likely that word had been acquired by that age. More specifically, this measure indexes how much children are using a word during a given age range. This allows us to examine not just whether iconic words are used earlier in childhood, but also whether they are used more frequently.

For our analyses, we computed the log 10 number of times each of the 644 words occurred across the seven age ranges 6-11, $12-17,18-23,24-29,30-35,36-41$, and 42-47 months in the ChildFreq database. The first 6 months of life was not included because only one transcript was available. This lack of data is expected because it is also a period that is typically considered to be prior to when children begin speaking their first words (Bergelson and Swingley, 2012). The raw frequency counts were normalized per 1 million occurrences. Given that the words come from hundreds of transcripts of children's speech at different ages, the frequency of occurrence in the database includes multiple occurrences from a given child.

\section{Results and Discussion}

We assessed the relationship among the five potential independent variables by correlating their measures on the 644 test words or some subset of the words when a measure was not available for some of the words. As shown in Table 3, parental input frequency was negatively correlated with all of the other four variables: parents utter fewer words that are high in iconicity, concreteness, and systematicity, and also fewer words that are difficult to articulate. Articulation difficulty was negatively correlated with iconicity, which means that iconic words tend to be easier to articulate and might contribute to a child's acquisition of these words. Concreteness and systematicity were positively correlated with articulation difficulty, so that these two variables might share the variance accounted for by articulation difficulty. The correlations among iconicity, concreteness, and systematicity were not significant, showing that these three concepts are formally distinct properties of these words. This is an important result as the field attempts to untangle the many influences on a child's vocabulary acquisition. The observed independence between systematicity and iconicity challenges Monaghan et al's (Monaghan et al., 2014) proposal that words could be iconic without being systematic. For instance, we find that shake, kick, and dark are high in iconicity

TABLE 3 | Pearson correlations among difficulty of articulation, parental input frequency, iconicity, concreteness, and systematicity.

\begin{tabular}{|c|c|c|c|c|}
\hline & $\begin{array}{c}\text { Parental } \\
\text { input } \\
\text { frequency }\end{array}$ & Iconicity & Concreteness & Systematicity \\
\hline $\begin{array}{l}\text { Difficulty of } \\
\text { articulation }\end{array}$ & $-0.407^{\star \star \star}$ & $-0.139^{\star \star \star}$ & $0.269^{\star \star \star}$ & $0.335^{\star \star \star}$ \\
\hline $\begin{array}{l}\text { Parental input } \\
\text { frequency }\end{array}$ & & $-0.132^{\star \star \star}$ & $-0.407^{\star \star \star}$ & $-0.174^{\star \star}$ \\
\hline Iconicity & & & 0.007 & 0.029 \\
\hline Concreteness & & & & -0.096 \\
\hline
\end{tabular}


but low in systematicity; and hair, stove, and orange are high in systematicity and low in iconicity.

To evaluate the relationship between the independent measures and children's word frequency, we report two sets of partial correlations. The partial correlation between an independent variable and a dependent variable removes the effects of one or more control variables from both the dependent variable and the independent variable (Cohen and Cohen, 2002). In the first set, we computed partial correlations of iconicity, difficulty of articulation, concreteness, and parental input frequency with the dependent variable children's log 10 word frequency. Systematicity was not included as an independent variable because its values were available for only 305 of the test words. The second analysis tested the influence of systematicity when the other four independent variables were partialed out.

Partial correlations of iconicity, difficulty of articulation, concreteness, and parental input frequency with the dependent variable children's log 10 word frequency are shown in Table 4. We used partial correlations in our analyses because we wanted to remove the effects of three of these four independent variables (iconicity, difficulty of articulation, concreteness, and parental input frequency) from both the dependent variable (children's $\log 10$ word frequency) and the independent variable being tested. All four variables show significant partial correlations at some of the age ranges. The positive influence of iconicity was highest at 6-11 months and decreased gradually with increasing age. To determine if the influence of iconicity on word frequency decreased with increasing age, we carried out a linear regression analysis with Fisher transformed correlations of the seven iconicity partial correlations as the dependent variable and the midpoint of the seven age ranges as the independent variable (Hedges and Olkin, 1985; https://en.wikipedia.org/wiki/Fisher_transformation). This analysis is a form of meta-regression that determines the linear change in a set of independent partial correlations across the levels of a quantitative explanatory variable. The linear effect of age accounted for 0.875 of the variance, $F(1,6)=34.90$, $p=0.002$. This analysis strongly supports the observation that the influence of iconicity on children's expressive language acquisition decreases with increasing age. This result supports the hypothesis that there should be a preponderance of iconic words early in vocabulary acquisition followed by an increasing number of non-iconic words.
The overall negative contribution of articulation difficulty on word frequency was significant at all age ranges, except for the youngest age group with a very small number of test words. This result replicates Massaro and Rowe (2015) findings. Concreteness was also positively correlated with children's production vocabulary, with its influence diminishing for the older age groups. Finally, the positive influence of log 10 parental input frequency was significant and increased systematically between ages 6 and 47 months revealing the strong contribution of this factor.

In the second analysis, the partial correlation of systematicity with the children's word frequencies was computed, controlling for the four independent variables' iconicity, difficulty of articulation, concreteness, and parental input frequency. Table 5 shows that there was no significant effect of this variable in the partial correlations at all seven age groups. This result differs from Monaghan et al.s (Monaghan et al., 2014) study, which correlated age-of-acquisition ratings (Kuperman et al., 2012) with the systematicity of 2,787 words. They found that more systematic words are learned earlier by children, especially for ages 2 and 3 (see Figure 5, Monaghan et al., 2014). The reason for why we did not find this pattern in current set of words-we had systematicity values for only 305 test items-will have to be resolved in future research.

Figure 1 gives the distribution of the iconicity ratings of the 644 words used in the experiment. The figure shows the predominance of iconic words -478 of the 644 words had positive iconicity values. This result suggests that children might come to expect words to be at least somewhat iconic, and therefore, they might be easily derailed when an opposite or even a neutral iconic word is encountered. We would expect that the complexity of vocabulary would increase with its size as the child matures, and characteristics of iconicity give way to arbitrariness. This allows other influences such as parental input to have even a larger impact on the child's vocabulary acquisition.

To perform a finer-grained analysis of how iconicity varies across the temporal course of vocabulary acquisition, we evaluated 4 groups of 26 words shown in Table 1 that were rated with high, some, neutral, or opposite iconicity (with average iconicity ratings of $2.97,1.06,0$, and -0.767 , respectively). As can be seen in Table 1, the high group with the highest iconicity ratings included obvious onomatopoeic words, which allowed us to examine the development of these words compared to words in the some

TABLE 4 | Partial correlations and significance values of each of the four independent variables iconicity, difficulty of articulation, concreteness, and log 10 parental input frequency carried out on the log 10 word child frequency at seven different age ranges (in months).

\begin{tabular}{|c|c|c|c|c|c|c|c|}
\hline Age range (months) & $6-11$ & $12-17$ & $18-23$ & $24-29$ & 30-35 & $36-41$ & $42-47$ \\
\hline Iconicity & $0.343^{\star \star}$ & $0.216^{\star \star \star}$ & $0.171^{\star \star \star}$ & $0.161^{\star \star \star}$ & $0.103^{\star}$ & $0.110^{\star \star}$ & -0.004 \\
\hline Difficulty of articulation & -0.160 & $-0.121^{\star \star}$ & $-0.166^{\star \star \star}$ & $-0.150^{\star \star \star}$ & $-0.158^{\star \star \star}$ & $-0.094^{*}$ & $-0.093^{*}$ \\
\hline Concreteness & $0.320^{\star \star}$ & $0.377^{\star \star \star}$ & $0.430^{\star \star \star}$ & $0.410^{\star \star \star}$ & $0.226^{\star \star \star}$ & $0.173^{\star \star \star}$ & 0.011 \\
\hline Log 10 parental frequency & $0.428^{\star \star \star}$ & $0.497^{\text {** }}$ & $0.731^{\star \star \star}$ & $0.838^{\star \star \star}$ & $0.869^{\star \star \star}$ & $0.890^{\star \star \star}$ & $0.865^{\star \star \star}$ \\
\hline df & 97 & 441 & 585 & 600 & 600 & 594 & 592 \\
\hline Number of words in database & 16,940 & 49,097 & 249,202 & 687,258 & 758,882 & 431,233 & 313,349 \\
\hline
\end{tabular}

Note that the number of words occurring in the ChildFreq database in the last row is due to the different sample sizes at the different age ranges. Note further that the differences in degrees of freedom (df) reflect cases in which one of the independent variables was not defined for a word, or a word did not occur in the database and the log 10 transformation is undefined and therefore not included in the analyses.

${ }^{*} p<0.05$.

${ }^{* *} p<0.01$.

${ }^{* * *} p<0.001$ 
TABLE 5 | Partial correlation and significance values for the independent variable systematicity carried out on the log 10 word child frequency at seven different age ranges (in months).

\begin{tabular}{|c|c|c|c|c|c|c|c|}
\hline Age range (months) & $6-11$ & $12-17$ & $18-23$ & $24-29$ & 30-35 & $36-41$ & $42-47$ \\
\hline Systematicity & 0.158 & -0.051 & -0.008 & 0.032 & 0.009 & 0.016 & 0.043 \\
\hline df & 44 & 237 & 294 & 298 & 299 & 299 & 296 \\
\hline Number of words in database & 16,940 & 49,097 & 249,202 & 687,258 & 758,882 & 431,233 & 313,349 \\
\hline
\end{tabular}

Note that the number of words occurring in the ChildFreq database in the last row is due to the different sample sizes at the different age ranges. Note further that the differences in degrees of freedom ( $d f$ reflect cases in which one of the independent variables was not defined for a word, or a word did not occur in the database and the log 10 transformation is undefined and therefore not included in the analyses.

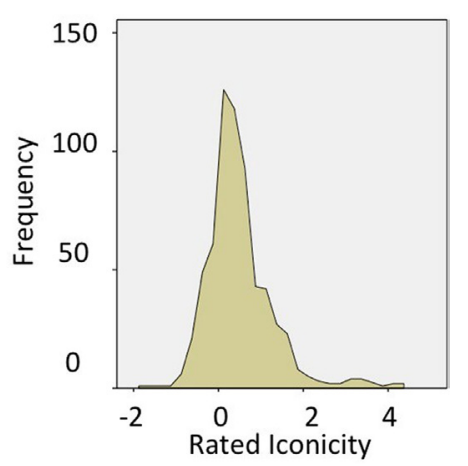

FIGURE 1 | Distribution of iconicity ratings for the 644 words from the MacArthur-Bates Communicative Development Inventories used in the iconicity ratings and the analyses in Experiment 1. iconicity group that are not so noticeably onomatopoeic. Also, it is informative to determine whether change in the use of words in the neutral group with ratings closest to 0 differs from words in the opposite group with the lowest iconicity ratings.

First, we zoomed in on word learning in the first months of life. We analyzed the ChildFreq database between 6 and 23 months in 3 -month periods. Figure 2 shows that words high in iconicity occur more often than the other three categories of words between 9 and 14 months. At 15-17 months, words with some and neutral iconicity are most frequent, and from 18 to 23 months, neutral iconicity words are most frequent. Words opposite in iconicity seldom occur in the first 14 months of life. Thus, a child's production vocabulary tends to begin with the frequent production of high iconicity words, and then over the next several months, moves toward words with some and neutral iconicity, and is eventually dominated by words some and neutral in iconicity. Words high and opposite in iconicity remain at a much lower frequency of occurrence.

Figure 3 gives a plot of the relationship between these four iconicity groups and frequency of occurrence in the ChildFreq database between 6 and 47 months in 6-month periods (Baath, 2014; ChildFreq, 2015). The 6-month periods camouflage the iconicity influence during the first 14 months seen in Figure 2 and also show that both high and opposite iconicity words become relatively much less frequent than words with some iconicity during development. Words with some iconicity occur more often and persist in the child's vocabulary but only at less than half of the frequency as words neutral in iconicity.

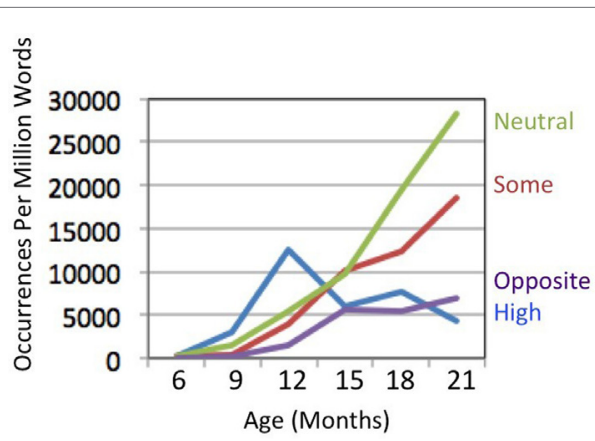

FIGURE 2 | The frequency of occurrence per 1 million words across age for the $\mathbf{4}$ groups of $\mathbf{2 6}$ words with high, some, neutral, and opposite iconicity. Age represents the 3-month intervals beginning with the age indicated on the abscissa. The production results taken from ChildFreq (Baath, 2014).

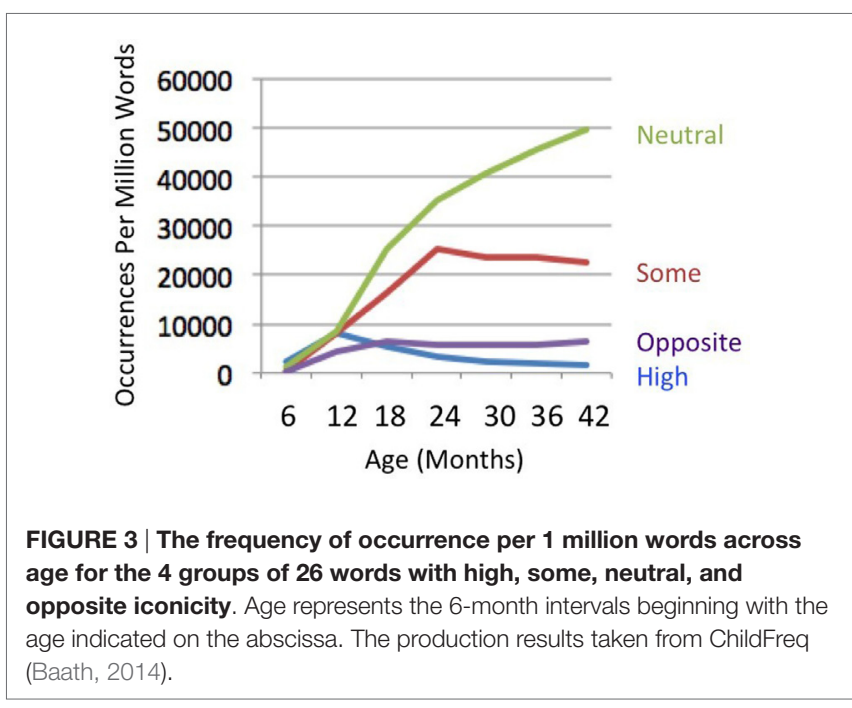

To summarize the first experiment, our analyses have shown a significant influence of iconicity early in language acquisition followed by a growing predominance of words with some and neutral iconicity. The productive vocabulary of very young children is thus characterized by a prevalence of highly iconic words becoming increasingly arbitrary over development. This relationship between iconicity and children's productive word frequency holds even after factoring out covariates such as concreteness, 
difficulty of articulation, and parental input frequency, which are known to influence word learning. In the next experiment, we use the data from individual children to test the hypothesis that the size of a child's vocabulary will be inversely related to iconicity. A child's first words should be highly iconic, and their vocabulary should become less iconic as new words are acquired. In addition to production vocabulary, we also assess the contribution of iconicity to receptive vocabulary, an analysis that has not been previously carried out in spoken language acquisition.

\section{EXPERIMENT 2: INDIVIDUAL CHILD'S RECEPTIVE AND PRODUCTIVE WORD OCCURRENCES ACROSS ACQUISITION}

\section{Method}

The database consisted of a parental report checklist of whether their child understood and produced 396 words, organized in different words categories such as animal sounds and vehicles (MCDI Words and Gestures American, 2016). The final dataset included 386 words after combining the list's duplicate words that had multiple meanings (e.g., water). There were 1,089 unique individual cases in which the words produced and understood were tabulated for a particular child at a given age (Fenson et al., 2007; Massaro and Rowe, 2015). The ages of the children ranged from 8 to 18 months. In contrast to previous analyses, the data analysis in this study was applied to each individual child's words rather than to group results. As is well known in the literature on receptive and productive vocabulary acquisition, there was a large range of the number of words understood and produced across the 1,089 children. In addition, the range and number of words understood far exceeded the comparable results for words produced (Massaro and Rowe, 2015).

Massaro and Rowe (2015) analyzed the differences between comprehension and production by grouping the individual subjects into six groups. The same six groups were used in the present analysis. The six groups and the number of subjects in each group were determined to give meaningful differences in the number of words that a child produced. That is the groups were determined to give relatively low variance within a group and high variance between groups. In the first group, for example, there were 176 cases in which no words were produced, and in only
5 overlapping cases were there also no words understood. The remaining 171 cases of children with no expressive vocabulary had between 1 and 341 words understood with an average of 45.6 words. A similar discrepancy between productive and receptive language is apparent for the other five groups shown in Table 6.

\section{Results and Discussion}

This variability in produced and understood words across the 1,089 children allows us to test the hypothesis that the iconicity of a child's known words will be highest for his or her first words and then decrease as additional words are learned. Table 6 gives the average iconicity for the six groups of children who varied in the number of words produced and understood. No iconicity values are given for produced words for the first group of children without any productive vocabulary, and the five subjects who did not understand any words did not contribute to the average iconicity for understood words. As can be seen in Table 6, there is a systematic decrease in the average iconicity of a child's words as more words are produced and understood. Produced words in particular are highly iconic in the child's very first words, and the degree of iconicity falls off steeply as the child's vocabulary grows in size. In line with this pattern, the much larger number of understood words may render the results for understood word less sensitive to the iconicity of a child's very first words.

It should be noted that we did not include systematicity, concreteness nor parental input frequency as covariates in this analysis because there was no rank order correlation between systematicity and iconicty $(r=0.034)$, concreteness and iconicity $(r=0.013)$, nor a correlation between iconicity and parental input frequency $(r=-0.024)$. Thus, this analysis should give a relatively pure measure of the influence of iconicity across increases in productive and receptive language.

A two-way ANOVA was carried out on the average iconicity values for each of the 907 subjects included in the analysis, with spoken versus understood words and the 5 groups as independent factors. The first group in Table 6 was not included in the analysis because this group had no productive words. As can be seen in Figure 4, the differences between produced and understood words and the differences across the five groups were highly significant, $F(1,1,814)=682.21, p<0.001 ; F(4,1,814)=83.04$, $p<0.001$, as was the interaction between the two variables,

TABLE 6 | Six partitions of the individual results of 1,089 children based on the number of words produced, giving the range and average of the number of words produced, the range and average number of words understood, the number of cases contributing to each partition of the analysis, and the average iconicity of the produced and understood words.

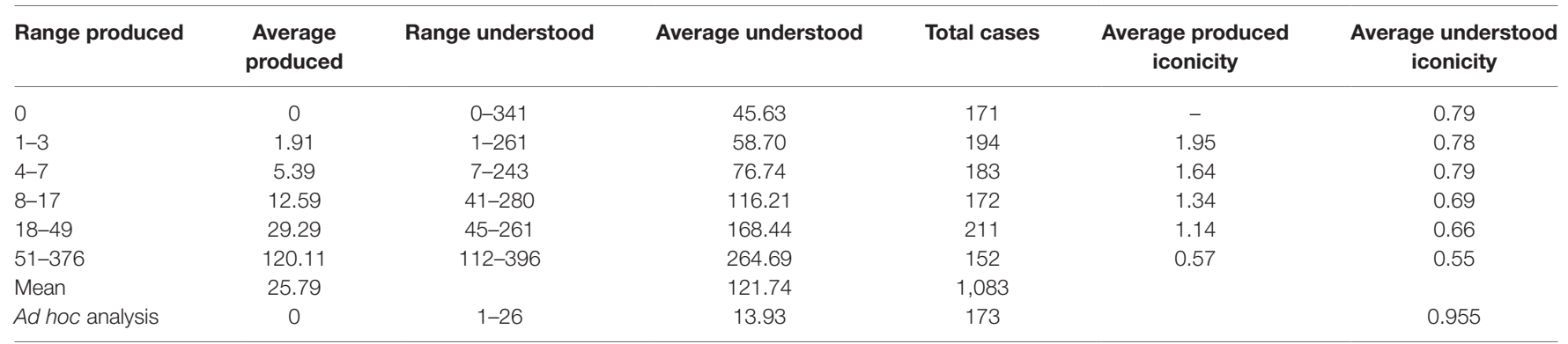

No average is given for the average produced iconicity for 0 produced words since no words were produced. 


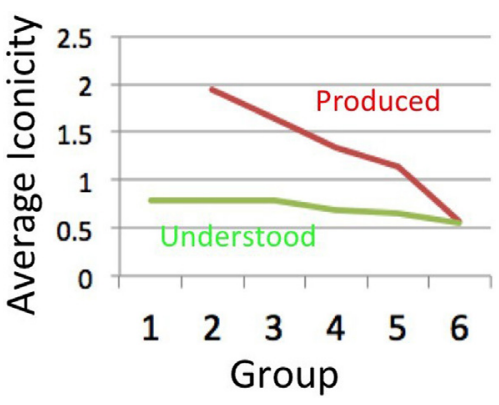

FIGURE 4 | Mean iconicity values of produced versus understood words as a function of the six groups with an increasing number of words in their produced or understood vocabulary. No results are shown for Group 1 produced words because these children did not produce any.

$F(4,1,814)=42.30, p<0.001$. A separate analysis on produced and understood words showed a statistically significant linear decrease in average iconicity values across the five groups for both produced and understood words, $F(1,907)=260.04$, $p<0.001$; $F(1,907)=94.93, p<0.001$.

We also computed Spearman correlations between the average iconicity of a child's produced or understood words with the number of words produced or understood. (We used Spearman correlations because we do not expect the number of words to conform to an interval scale.) There was a negative Spearman correlation of $-0.450, p<0.001$ (913 cases) between the number of words a child produced and the average iconicity of those words, and also a Spearman negative correlation of $-0.600, p<0.001$ $(1,084$ cases) between the number of understood words and their average iconicity. The correlation is significantly more extreme for understood words than produced words, $z=4.45, p<0.001$. Although the size of the effect of iconicity in Table 6 has a much smaller range for understood words than for produced words, the significant difference between the two correlations shows a more systematic linear relationship for understood than produced words. The higher correlation for understood words might simply reflect a more consistently distributed result in understood relative to produced words. Recall there were 171 children who produced no words and only 5 who understood no words.

Figure 5 plots the average rated iconicity of the words that a child produced as a function of the size of the child's productive vocabulary. Figure 6 gives the analogous results for words understood. As can be seen in these two figures, the average iconicity of a child's vocabulary diminishes dramatically with increases in vocabulary size.

One potential limitation of our separate analyses of produced and understood words database is that all words that were checked off as produced were automatically scored as understood (see Fenson et al., 1993; Massaro and Rowe, 2015). To eliminate this overlap as much as possible we chose 410 children who produced 9 or fewer words. Thus, the bulk of the understood words would not be from produced words being checked off and therefore should be a reasonably pure measure of understood words. For these 410 children, the Spearman correlation between average iconicity

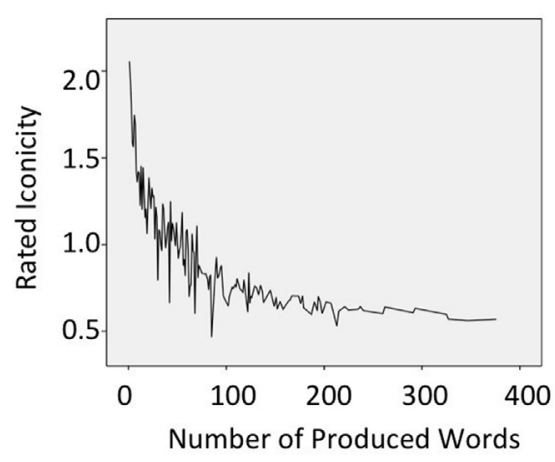

FIGURE 5 | Average rated iconicity of the words that a child produced as a function of the frequency of occurrence of the number of words the child produced.

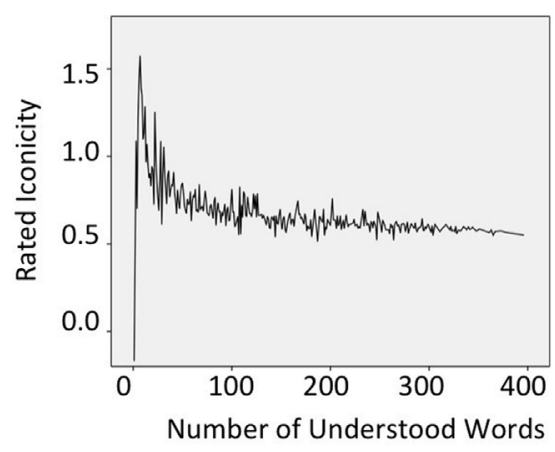

FIGURE 6 | Average rated iconicity of the words that a child understood as a function of the frequency of occurrence of the number of words the child understood.

and number of understood words was $-0.441, p<0.001$. This negative correlation is consistent with the hypothesis that a child's comprehension of vocabulary is such that earlier understood words are more iconic than later understood words. This result is unlikely to be contaminated by the scoring procedure used to create the database.

For the 194 children who produced 1,2, or 3 words, the average iconicity was 1.95 . Unfortunately, there were only 11 children that understood 1-3 words, which precludes a direct comparison between these two groups. Future research will require a database with a large number of children who understand very few words. When iconic words are first spoken, most children already have a relatively large set of understood words that tend to be less iconic or even non-iconic (see Table 6).

The Spearman correlation between the average iconicity of produced words and the average iconicity of understood words across the 913 children was 0.315 . Words most understood also tend to be the most produced. Of the 20 most frequent understood words, 12 were also produced: ball, book, bottle, bye, daddy, dog, hi, mommy, nice, no, uhoh, and water. The eight most understood words not in the set of the 20 most frequent produced words 
were allgone, bath, diaper, eat, juice, kiss, peekaboo, and shoe. Of the 20 most frequent produced words, 8 were not in the set of the 20 most understood words: baabaa, baby, duck, grr, kitty, vroom, woofwoof, and yumyum. Many of these tend to be classic onomatopoeia words, several of which incorporate reduplication.

To see if the larger range of the number of understood words compared to produced words contributed to the observed difference between the understood and produced iconicity functions in Figure 4, we found 173 children that had an understood vocabulary of 1-26 words, with an average of 13.93 words. The average iconicity for understood words across these 173 children was 0.955 . This value is significantly smaller than the average iconicity of 1.34 for produced words for a comparable 172 children with an average production vocabulary of 12.59 words, ranging from 8 to 17 words. Thus, the distribution of the number of words in understood versus productive vocabulary does not appear to be completely responsible for the difference between the understood and produced iconicity functions. The earliest words that a child produces appear to be more iconic than the rest of the words that comprise the child's receptive vocabulary. This result is analogous to a previous finding that difficulty of articulation had a bigger impact on the acquisition of words in productive use than in understanding (Massaro and Rowe, 2015).

To provide another assessment of whether the number of produced and understood words in a child's vocabulary gives the same interaction with iconicity, we combined the results from these two measures into a single data set. We eliminated the 176 children with 0 words produced from the produced words data, and the 5 children with 0 words understood from the understood words data. This gave a total of 1,997 data points to compute a correlation between number of words in the child's vocabulary and the average iconicity of those words.

Figure 7 shows a systematic relationship between the number of words in a child's vocabulary and the average iconicity of those words. The Spearman correlation was $-0.695, p<0.001$, which is strong evidence that a child with fewer words in their (produced or understood) vocabulary will tend to have words with higher iconicity. This correlation with both produced and understood words is significantly higher than the correlation with just produced words, $z=9.32, p<0.001$, and the correlation with

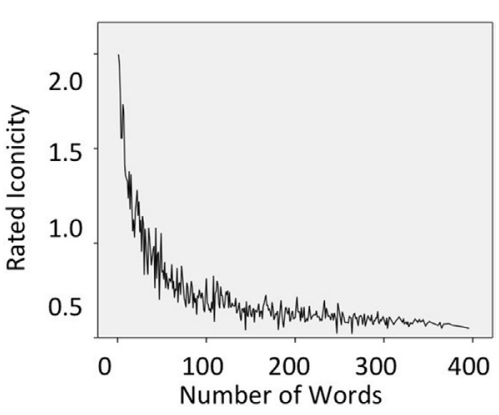

FIGURE 7 | Mean-rated iconicity of the words that a child produced or understood as a function of the frequency of occurrence of the number of words the child produced or understood. just understood words, $z=4.35, p<0.001$. The larger correlation obtained by combining both produced and understood words than either of the two separate correlations with produced and with understood words as well as the continuous relationship shown in Figure 7 indicate that iconicity appears to influence both produced and understood words in a roughly similar way.

Altogether, the findings of Experiment 2 support the hypothesis that a child's first words tend to be more iconic, both in comprehension and production. This is generally consistent with the hypothesis that iconic words will be learned early in vocabulary acquisition.

\section{GENERAL DISCUSSION}

We have demonstrated an influence of iconicity on children's early vocabulary learning in two different experiments. In Experiment 1 , we found a significant relationship between iconicity and the frequency of words used by children across early vocabulary development, even after controlling for several other variables known to influence word learning. The findings of Experiment 2 again found a significant relationship between iconicity and word learning, this time with production and understanding inventories from individual children.

Our findings are generally consistent with the hypothesis that iconicity plays an influential role in bootstrapping early word learning. Recently, some developmental psychologists have proposed that learning iconic words facilitates the learning of non-iconic words by helping young children to realize the symbolic connection between words and meanings (Imai and Kita, 2014; Perniss and Vigliocco, 2014). Imai et al. (2008) found that children were able to generalize action words across agents when the verb was iconic of the action, but not when the verb was not iconic. However, the study did not test whether children who were trained in the iconic condition would generalize their learning to a non-iconic condition (which was not otherwise learned). Instead, the results to date simply indicate that children appear to be more inclined to learn and use more iconic words during the earliest stages of word learning. While our findings cannot distinguish between these two alternatives, they do point to the need to take iconicity into account in a theory of early word learning.

One possible criticism of our findings relating iconicity to word learning is that they are based on subjective ratings of words. This methodology is not unusual, however. Many other properties of words that have been evaluated are also determined subjectively, including age of acquisition, familiarity, sensory dominance, affect, concreteness, and imageability.

There is no doubt that there are multiple influences in vocabulary acquisition (Goodman et al., 2008; Massaro and Rowe, 2015; Hsu et al., 2017) and demonstrating the role for one influence requires accounting for all of the others. For example, Waxman et al. (2013) demonstrate an important role of non-iconic universal features on early language acquisition and conceptual development across different languages. A child's ability to learn the meaning of a novel verb is influenced by the particular language they are acquiring and the linguistic contexts in which the verb 
occurs (Roy et al., 2015). In addition to understanding the variables studied in current research, it is also important to determine how iconicity interacts with the semantic, morphologic, syntactic, and pragmatic properties of each language.

Consistent with this previous literature, we found that other variables besides iconicity-parental input frequency, concreteness (highly correlated with imageability), and difficulty of articulation-also made significant contributions to word learning. These findings support the broader framework that multiple sources of information are influential in language processing (Massaro, 1987, 1998; Movellan and McClelland, 2001) and language learning (Hirsh-Pasek et al., 2000), as well as word learning in particular (Goodman et al., 2008; Waxman et al., 2013; Massaro and Rowe, 2015; Hsu et al., 2017). For example, Hirsh-Pasek et al.s Emergentist Coalition Model describes how children rely on multiple cues over development in the mapping of words onto referents, with the use of and the weight given to these cues changing across development. The present findings indicate that a complete model of word learning also should include the influences of iconicity, parental input, difficulty of articulation, and concreteness (imageability).

\section{CONCLUSION}

These results contribute to an accumulating collection of studies revealing a significant role of iconicity in language acquisition and in language more broadly, including spoken and signed languages (Nuckolls, 1999; Taub, 2001; Imai and

\section{REFERENCES}

Baath, R. (2014). ChildFreq: An Online Tool to Explore Word Frequencies in Child Language. Available at: http://childes.psy.cmu.edu/topics/childfreq.pdf

Bates, E., and Goodman, J. C. (1999). "On the emergence of grammar from the lexicon," in The Emergence of Language, ed. B. MacWhinney (Mahwah, NJ: Lawrence Erlbaum), 29-79.

Bergelson, E., and Swingley, D. (2012). At 6-9 months, human infants know the meanings of many common nouns. Proc. Natl. Acad. Sci. U.S.A 109, 3253-3258. doi:10.1073/pnas.1113380109

Bergen, B. K. (2004). The psychological reality of phonaesthemes. Language 80, 290-311. doi:10.1353/lan.2004.0056

Blasi, D. E., Wichmann, S., Hammarstrom, H., Stadler, P. F., and Christiansen, M. H. (2016). Sound-meaning association biases evidenced across thousands of languages. Proc. Natl. Acad. Sci. U.S.A. 113, 10818-10823. doi:10.1073/ pnas.1605782113

Brysbaert, M., Warriner, A. B., and Kuperman, V. (2014). Concreteness ratings for 40 thousand generally known English word lemmas. Behav. Res. Methods 46, 904-911. doi:10.3758/s13428-013-0403-5

CHILDES. (2015). Available at: http://childes.psy.cmu.edu/

ChildFreq. (2015). Available at: http://childfreq.sumsar.net/

Christiansen, M. H., and Chater, N. (2016). Creating Language: Integrating Evolution, Acquisition, and Processing. Cambridge, MA: MIT Press.

Cohen, J., and Cohen, P. (2002). Applied Multiple Regression/Correlation Analysis for the Behavioral Sciences, 3rd Edn. New York: Routledge.

Dingemanse, M. (2012). Advances in the cross-linguistic study of ideophones. Lang. Linguist. Compass 6, 654-672. doi:10.1002/Inc3.361

Dingemanse, M., Blasi, D. E., Lupyan, G., Christiansen, M. H., and Monaghan, P. (2015). Arbitrariness, iconicity and systematicity in language. Trends Cogn. Sci. 19, 603-615. doi:10.1016/j.tics.2015.07.013

Fenson, L., Dale, P., Reznick, J., Bates, E., Thal, D., and Pethick, S. (1994). Variability in early communicative development. Monogr. Soc. Res. Child Dev. 59, 1-173. doi:10.2307/1166093
Kita, 2014; Perlman and Cain, 2014; Perniss and Vigliocco, 2014; Dingemanse et al., 2015; Perlman et al., 2015; Perry et al., 2015). In particular, this study provides a detailed quantification of how the iconicity of learned words varies across vocabulary development, and the only one to date including both receptive understanding and production. We found in two experiments with two different databases and with different analyses that iconicity is most prevalent in the earliest acquired words and diminishes with increasing age and increasing vocabulary. Thus, these new results support the hypothesis that a child's first words tend to be iconic.

\section{AUTHOR CONTRIBUTIONS}

DM and MP both developed the research questions, design, and data analyses and wrote the manuscript. DM carried out the data analyses.

\section{ACKNOWLEDGMENTS}

The authors would like to thank Larry Fenson, Virginia Marchman, and the advisory board of the MacArthur-Bates Communicative Development Inventories (CDI) for making the data from individual children available for the current analyses in Experiment 2, Philip Dale for providing the parental input frequencies, and Doug Bonnet for extremely helpful statistical advice. The authors also thank the two referees for their helpful evaluation of the research and paper.

Fenson, L., Dale, P. S., Reznick, J. S., Thal, D., Bates, E., Hartung, J. P., et al. (1993). The MacArthur Communicative Development Inventories: User's Guide and Technical Manual. Baltimore: Paul H. Brookes Publishing Co.

Fenson, L., Marchman, V. A., Thal, D. J., Dale, P. S., Reznick, J. S., and Bates, E. (2007). MacArthur-Bates Communicative Development Inventories: User's Guide and Technical Manual, 2nd Edn. Baltimore: Paul H. Brookes.

Gentner, D. (1982). "Why nouns are learned before verbs: linguistic relativity versus natural partitioning," in Language Development: Vol 2. Language, Thought, and Culture, ed. S. A. Kuczaj II (Hillsdale, NJ: Erlbaum), 31-53.

Gentner, D., and Boroditsky, L. (2001). "Individuation, relativity, and early word learning," in Language Acquisition and Conceptual Development, eds M. Bowerman and S. C. Levinson (Cambridge, England: Cambridge University Press), 215-256.

Gillette, J., Gleitman, H., Gleitman, L., and Lederer, A. (1999). Human simulation of vocabulary learning. Cognition 73, 135-176. doi:10.1016/ S0010-0277(99)00036-0

Goodman, J. C., Dale, P. S., and Li, P. (2008). Does frequency count? Parental input and the acquisition of vocabulary. J. Child Lang. 35, 515-531. doi:10.1017/ S0305000907008641

Hart, B., and Risley, T. (1995). Meaningful Differences in the Everyday Experience of Young American Children. Baltimore, CA: Paul H. Brookes.

Hedges, L. V., and Olkin, I. (1985). Statistical Methods for Meta-Analysis. Orlando, FL: Academic Press.

Hirsh-Pasek, K., Golinkoff, R. M., and Hollich, G. (2000). "An emergentist coalition model for word learning: mapping words to objects is a product of the interaction of multiple cues," in Becoming a Word Learner: A Debate on Lexical Acquisition, eds R. M. Golinkoff, K. Hirsh-Pasek, L. Bloom, L. Smith, A. Woodward, N. Akhtar, et al. (New York, NY: Oxford University Press), 136-164.

Hockett, C. F. (1960). The origin of speech. Sci. Am. 203, 88-96. doi:10.1038/ scientificamerican0960-88

Hsu, N., Hadley, P. A., and Rispoli, M. (2017). Diversity matters: parent input predicts toddler verb production. J. Child Lang. 44, 63-86. doi:10.1017/ S0305000915000690 
Imai, M., and Kita, S. (2014). The sound symbolism bootstrapping hypothesis for language acquisition and language evolution. Philos. Trans. R. Soc. Lond. B Biol. Sci. 369, 20130298. doi:10.1098/rstb.2013.0298

Imai, M., Kita, S., Nagumo, M., and Okada, H. (2008). Sound symbolism facilitates early verb learning. Cognition 109, 54-65. doi:10.1016/j.cognition.2008. 07.015

Imai, M., Miyazaki, M., Yeung, H. H., Hidaka, S., Kantartzis, K., Okada, H., et al. (2015). Sound symbolism facilitates word learning in 14-month-olds. PLoS ONE 10:e0116494. doi:10.1371/journal.pone.0116494

Kantartzis, K., Imai, M., and Kita, S. (2011). Japanese sound-symbolism facilitates word learning in English-speaking children. Cogn. Sci. 2011, 575-586. doi:10.1111/j.1551-6709.2010.01169.x

Kirk, C. (2008). Substitution errors in the production of word-initial and word-final consonant clusters. J. Speech Lang. Hear. Res. 51, 1-14. doi:10.1044/1092-4388(2008/003)

Kirk, C., and Demuth, K. (2005). Asymmetries in the acquisition of word-initial and word-final consonant clusters. J. Child Lang. 32, 709-734. doi:10.1017/ S0305000905007130

Klima, E., and Bellugi, U. (1979). The Signs of Language. Cambridge, MA: Harvard University Press.

Köhler, W. (1947). Gestalt Psychology, 2nd Edn. New York: Liveright.

Kuperman, V., Stadthagen-Gonzalez, H., and Brysbaert, M. (2012). Ageof-acquisition ratings for 30,000 English words. Behav. Res. Methods 44, 978-990. doi:10.3758/s13428-012-0210-4

Lewis, M. L., and Frank, M. C. (2016). The length of words reflects their conceptual complexity. Cognition, 153, 182-195.

MacWhinney, B. (2000). The CHILDES Project, 3rd Edn. Mahwah, NJ: Erlbaum. Available at: http://childes.psy.cmu.edu/derived/parentfreq.cdc

Maguire, M., Hirsh-Pasek, K., and Golinkoff, R. M. (2006). "A unified theory of word learning: putting verb acquisition in context," in Action Meets Word: How Children Learn Verbs, eds K. Hirsh-Pasek and R. M. Golinkoff (New York, NY: Oxford University Press), 364-391.

Markman, E. (1990). Constraints children place on word meanings. Cogn. Sci. 14, 57-77. doi:10.1207/s15516709 $\operatorname{cog} 1401 \_4$

Markman, E. M. (1991). "The whole-object, taxonomic, and mutual exclusivity assumptions as initial constraints on word meanings," in Perspectives on Language and Thought: Interrelations in Development, eds S. A. Gelman, J. P. Byrnes, S. A. Gelman, and J. P. Byrnes (New York, NY: Cambridge University Press), 72-106.

Massaro, D. W. (1987). Speech Perception by Ear and Eye: A Paradigm for Psychological Inquiry. Hillsdale, NJ: Erlbaum.

Massaro, D. W. (1998). Perceiving Talking Faces: From Speech Perception to a Behavioral Principle. Cambridge, MA: MIT Press.

Massaro, D. W. (2016). "Multiple influences in vocabulary acquisition: parental input dominates," in Proceedings of the 17th Annual Conference of the International Speech Communication Association (Interspeech 2016), 878-882. Available at: www.isca-speech/archive/interspeech_2016/pdfs/0037.PDF

Massaro, D. W., and Rowe, B. (2015). Comprehension outscores production in language acquisition: implications for theories of vocabulary learning. J. Child Lang. Acquis. Dev. 3, 121-152.

McAllister Byun, T. (2012). Bidirectional perception-production relations in phonological development: evidence from positional neutralization. Clin. Linguist. Phon. 26, 397-413. doi:10.3109/02699206.2011.641060

MCDI Words and Gestures American. (2016). Available at: http://www.cdi-clex. org/vocabulary/about/index/corpora/1

McDonough, C., Song, L., Pasek, K. H., Golinkoff, R. M., and Lannon, R. (2011). An image is worth a thousand words: why nouns tend to dominate verbs in early word learning. Dev. Sci. 14, 181-189. doi:10.1111/j.1467-7687.2010.00968.x

Monaghan, P., Shillcock, R. C., Christiansen, M. H., and Kirby, S. (2014). How arbitrary is language? Philos. Trans. R. Soc. Lond. B Biol. Sci. 369, 20130299. doi:10.1098/rstb.2013.0299

Movellan, J., and McClelland, J. L. (2001). The Morton-Massaro law of information integration: implications for models of perception. Psychol. Rev. 108, 113-148. doi:10.1037/0033-295X.108.1.113

MRCDatabase. (2015). Available at: http://websites.psychology.uwa.edu.au/ school/MRCDatabase/mrc2.html

Nuckolls, J. B. (1999). The case for sound symbolism. Annu. Rev. Anthropol. 28, 225-252. doi:10.1146/annurev.anthro.28.1.225
Nygaard, L. C., Cook, A. E., and Namy, L. L. (2009). Sound to meaning correspondences facilitate word learning. Cognition 112, 181-186. doi:10.1016/ j.cognition.2009.04.001

Ohala, J. J. (1994). "The frequency code underlies the sound symbolic use of voice pitch," in Sound Symbolism, eds L. Hinton, J. Nichols, and J. J. Ohala (Cambridge: Cambridge University Press), 325-347.

Orlansky, M. D., and Bonvillian, J. D. (1984). The role of iconicity in early sign language acquisition. J. Speech Hear. Disord. 49, 287. doi:10.1044/jshd.4903.287

Paivio, A., Yuille, J. C., and Madigan, S. A. (1968). Concreteness, imagery, and meaningfulness values for 925 nouns. J. Exp. Psychol. 76(1, Pt. 2), 1-25. doi:10.1037/h0025327

ParentFreq. (2015). Available at: http://childes.psy.cmu.edu/derived/parentfreq. $\mathrm{cdc}$

Perlman, M., and Cain, A. (2014). Iconicity in vocalizations, comparisons with gesture, and implications for the evolution of language. Gesture 14, 320-350. doi:10.1075/gest.14.3.03per

Perlman, M., Dale, R., and Lupyan, G. (2015). Iconicity can ground the creation of vocal symbols. R. Soc. Open Sci. 2, 150152. doi:10.1098/rsos.150152

Perniss, P., and Vigliocco, G. (2014). The bridge of iconicity: from a world of experience to the experience of language. Philos. Trans. R. Soc. B Biol. Sci. 2014, 20130300. doi:10.1098/rstb.2013.0300

Perry, L. K., Perlman, M., and Lupyan, G. (2015). Iconicity in English and Spanish and its relation to lexical category and age of acquisition. PLoS ONE 10:e0137147. doi:10.1371/journal.pone.0137147

Pinker, S., and Bloom, P. (1990). Natural language and natural selection. Behav. Brain Sci. 13, 707-784. doi:10.1017/S0140525X00081061

Quine, W. V. O. (1960). Word and Object: An Inquiry into the Linguistic Mechanisms of Objective Reference. Cambridge, MA: MIT Press.

Quine, W. V. O. (1990/1992). Pursuit of Truth. Cambridge, MA: Harvard University Press.

Ramachandran, V. S., and Hubbard, E. M. (2001). Synaesthesia: a window into perception, thought and language. J. Conscious Stud 8, 3-34.

Rhodes, R. (1994). "Aural images," in Sound Symbolism, eds L. Hinton, J. Nichols, and J. J. Ohala (Cambridge: Cambridge University Press), 276-292.

Roy, B. C., Frank, M. C., DeCamp, P., Miller, M., and Roy, D. (2015). Predicting the birth of a spoken word. Proc. Natl. Acad. Sci. U.S.A. 112, 12663-12668. doi:10.1073/pnas.1419773112

Rvachew, S., Chiang, P., and Evans, N. (2007). Characteristics of speech errors produced by children with and without delayed phonological awareness skills. Lang. Speech Hear. Serv. Sch. 38, 60-71. doi:10.1044/0161-1461(2007/006)

Shriberg, L. (1993). Four new speech and prosody-voice measures for genetics research and other studies in developmental phonological disorders. J. Speech Hear. Res. 36, 105-140. doi:10.1044/jshr.3601.105

Signing Savvy. (2016). Available at: https://www.signingsavvy.com/wordlist/27479/ sign $\% 20160 \% 20$ iconic\%20signs

Smit, A. B. (1993). Phonologic error distributions in the Iowa-Nebraska Articulation Norms Project: consonant singletons. J. Speech Hear. Res. 36, 533-547. doi:10.1044/jshr.3603.533

Smit, A. B., Hand, L., Freilinger, J. J., Bernthal, J. E., and Bird, A. (1990). The Iowa Articulation Norms Project and its Nebraska replication. J. Speech Hear. Disord. 55, 779-798. doi:10.1044/jshd.5504.779

Snedeker, J., and Gleitman, L. (2004). "Why it is hard to label our concepts," in Weaving a Lexicon, eds G. Hall and S. Waxman (Cambridge, MA: MIT Press), 257-294.

Stoel-Gammon, C., and Buder, E. (1999). "Vowel length, post-vocalic voicing and VOT in the speech of two-year olds," in Proceedings of the XIIIth International Conference of Phonetic Sciences (San Francisco), Vol. 3, 2485-2488.

Taub, S. (2001). Language from the Body: Iconicity and Metaphor in American Sign Language. Cambridge: Cambridge University Press.

Thompson, R. L. (2011). Iconicity in language processing and acquisition: what signed languages reveal. Lang. Linguist. Compass 5, 603-616. doi:10.1111/ j.1749-818X.2011.00301.x

Thompson, R. L., Vinson, D. P., Woll, B., and Vigliocco, G. (2012). The road to language learning is iconic: evidence from British Sign Language. Psychol. Sci. 23, 1443-1448. doi:10.1177/0956797612459763

Tomasello, M., and Mervis, C. B. (1994). The instrument is great, but measuring comprehension is still a problem. Monogr. Soc. Res. 59, 174-179. doi:10.111 1/j.1540-5834.1994.tb00186.x 
Ultan, R. (1978). "Size-sound symbolism," in Universals of Human Language, eds J. H. Greenberg, C. R. Ferguson, and E. A. Moravcsik (Stanford, CA: Stanford University Press), 527-568.

Urban, M. (2011). Conventional sound symbolism in terms for organs of speech: a cross-linguistic study. Folia Linguist. 45, 199-214. doi:10.1515/ flin.2011.007

Vinson, D. P., Cormier, K., Denmark, T., Schembri, A., and Vigliocco, G. (2008). The British Sign Language (BSL) norms for age of acquisition, familiarity, and iconicity. Behav. Res. Methods 40, 1079-1087. doi:10.3758/BRM.40.4.1079

Voeltz, E. F. K., and Kilian-Hatz, C. (2001). Ideophones. Amsterdam: John Benjamins Publishing Company.

Vosoughi, S., Roy, B. C., Frank, M. C., and Roy, D. (2010). "Effects of caregiver prosody on child language acquisition," in Proceedings of the 5th International Conference on Speech Prosody (Chicago, IL).

Waxman, S. R. (1999). Specifying the scope of 13-month-olds' expectations for novel words. Cognition 70, B35-B50. doi:10.1016/S0010-0277(99) 00017-7

Waxman, S. R., Fu, X., Arunachalam, S., Leddon, E., Geraghty, K., and Song, H. J. (2013). Are nouns learned before verbs? Infants provide insight into a long-standing debate. Child Dev. Perspect. 7, 155-159. doi:10.1111/cdep.12032
Winter, B., Perlman, M., Perry, L., and Woll, B. (In press). Which words are most iconic? Iconicity in English sensory words. Interaction Studies

Woolfe, T., Herman, R., Roy, P., and Woll, B. (2010). Early vocabulary development in deaf native signers: a British Sign Language adaptation of the communicative development inventories. J. Child Psychol. Psychiatry 51, 322-331. doi:10.1111/j.1469-7610.2009.02151.x

WordBank. (2016). Available at: http://wordbank.stanford.edu/

Yoshida, H. A. (2012). Cross-linguistic study of sound symbolism in children's verb learning. J. Cogn. Dev. 13, 232-265. doi:10.1080/15248372.2011.573515

Conflict of Interest Statement: The authors declare that the research was conducted in the absence of any commercial or financial relationships that could be construed as a potential conflict of interest.

Copyright (C) 2017 Massaro and Perlman. This is an open-access article distributed under the terms of the Creative Commons Attribution License (CC BY). The use, distribution or reproduction in other forums is permitted, provided the original author(s) or licensor are credited and that the original publication in this journal is cited, in accordance with accepted academic practice. No use, distribution or reproduction is permitted which does not comply with these terms. 


\section{APPENDIX}

\section{Instructions for the Iconicity Rating Study}

Some English words sound like what they mean. For example, SLURP sounds like the noise made when you perform this kind of drinking action. An example that does not relate to the sound of an action is TEENY, which sounds like something very small (compared to HUGE which sounds big). These words are iconic. You might be able to guess these words' meanings even if you did not know English. Words can also sound like the opposite of what they mean. For example, MICROORGANISM is a large word that means something very small. And WHALE is a small word that means something very large. And finally, many words are not iconic or opposite at all. For example, there is nothing canine or feline sounding about the words DOG or CAT. These words are arbitrary. If you did not know English, you would not be able to guess the meanings of these words.

Your task is to rate each word, one at a time, on a scale from -5 to 5 such that -5 indicated words that sound like the opposite of what they mean, 5 indicated words that sound like what they mean, and 0 indicated words that are arbitrary-do not sound like what they mean or the opposite. A -3 rating would mean that the word sounds somewhat like the opposite of its meaning, but not completely. A 3 rating would mean that the word sounds somewhat like its meaning, but not completely.

Are there any questions? 